\title{
A prática educativa como uma atividade de desencontro de sujeitos
}

Rogério Rodrigues

Universidade Federal de Itajubá

\section{Resumo}

Os educadores, de modo geral, partem do princípio de que a prática educativa é algo que surge na transmissão de saberes provenientes do encontro entre sujeitos. Entretanto, nas relações que se estabelecem entre os sujeitos, principalmente, naquilo que orbita no campo do uso da palavra, vive-se o que podemos denominar como o mal-entendido, pois falamos o que não pensamos e escutamos o que não foi dito. No campo educativo, portanto, assumimos a convicção profunda de que as relações são de encontro entre sujeitos, mas paradoxalmente e para desespero dos educadores, temos na prática educativa uma atividade de desencontro de sujeitos. Neste artigo, o objetivo é analisar a prática educativa na dinâmica do desencontro de sujeitos. São tais desencontros que de certo modo abrem as fendas no saber pedagógico e evidenciam a fragilidade desses saberes educativos. Partimos da perspectiva freudiana anunciada em prefácio do livro de August Aichhorn (1925), em que se inscreve a afirmação de que existem três profissões impossíveis - educar, curar e governar. A nossa hipótese é a de que a prática educativa é a realização de uma tarefa que exige do educador uma constante desconstrução de seus princípios pedagógicos que coisificam o sujeito/educando - o desamparo de não sabermos educar.

\section{Palavras-chave}

Educação - Educação e Psicanálise - Pedagogia.

Correspondência: 


\title{
Educative practice as an activity of disaccord between subjects
}

Rogério Rodrigues

Universidade Federal de Itajubá

\begin{abstract}
Broadly speaking, educators assume that the educative practice is something that takes place in the transmission of knowledges that emerges out of an encounter between subjects. However, in the relations established between the subjects, and especially in what concerns the field of the use of words, one experiences what can be described as a "misunderstanding", for we say what we do not think, and hear what has not been said. In the educative field we therefore have the profound conviction that the relations are of encounter between subjects, when, paradoxically and to the educators' despair, we actually have an activity of disaccord between subjects. In this article, we seek to analyze educative practices in the dynamics of the disaccord between subjects. It is this disaccord that in a certain sense reveals the chink in the pedagogical knowledge, and evinces the fragility of these educational knowledges. We assume the Freudian perspective put forward in the preface to the book by August Aichhorn (1925), in which we find the statement that there are three impossible professions: educating, curing, and governing. Our hypothesis is that the educative practice is the accomplishment of a task that requires from the educators a permanent deconstruction of the pedagogical principles that "thingify" the subject/educated - the desolation of not knowing how to educate.
\end{abstract}

\section{Keywords}

Education - Education and psychoanalysis - Pedagogy. 
0 mais importante de tudo na preparação para relações íntimas bem-sucedidas na maturidade é a experiência de ter recebido afeto na infância. Como disse uma de minhas filhas (de treze anos) quando a supervisora do acampamento não conseguiu cuidar dela direito: 'Os pais dela não cuidaram dela direito, e por isso ela não podia cuidar dela mesma, nem consegue agora cuidar de mim?. (Bruno Bettelheim).

\section{A crença na educação como encontro entre sujeitos}

Os educadores, de modo geral, partem do princípio de que a prática educativa ocorre na transmissão de saberes provenientes do encontro entre sujeitos, pois nessa situação consideram que se proporcionam as condições necessárias para que se estabeleçam as trocas simbólicas entre eles. Por quais motivos deveríamos nos deter na questão do desencontro entre estes para se pensar a prática educativa? Nesse caso, partimos do seguinte questionamento: será mesmo que os sujeitos se encontram na prática educativa?

Compreendemos o campo educacional como sendo uma tentativa de relação entre sujeitos que tem como pressuposto a transmissão de determinados ensinamentos. Os sujeitos na relação têm algo a dizer um para o outro. Contudo, paradoxalmente, essa relação acabou por se constituir como um desencontro de sujeitos, pois nada queremos saber sobre o outro da relação. Podemos analisar esse fato na prática educativa na situação em que a relação entre sujeitos é instituída como uma atuação normativa, na qual os pedagogos rigidamente sabem e definem o que é ser sujeito, principalmente como devemos proceder para educar o outro. Esses saberes pedagógicos acabam muitas vezes anulando o outro, pois se constituem em saberes a priori do encontro e definem a relação educativa mesmo que para isso seja preciso recusar a existência do outro. Portanto, a tese pedagógica da atividade educativa como encontro de sujeito encontra-se destinado ao fracasso, constitui-se na ilusão, principalmente, na anulação do outro, pois rigidamente fixamos o ser no que acreditamos e não reconhecemos que nada sabemos em ser sujeitos ${ }^{1}$. Como isso se observa no cotidiano escolar?

Partimos da suposição de que não precisamos formular uma pesquisa de campo na área educacional para constatar a crise do sujeito, pois para aqueles que são professores e alunos que vivem no ambiente educacional constatam discordâncias que indicam que a nossa idéia de sujeito não correspondem mais às experiências de relações humanas que realizamos no cotidiano escolar. Algo que não se compreende perante o outro e isso que não se enquadra são tidos como o problema pedagógico. Nesse caso, em vez de enfrentarmos a crise do sujeito, optamos por tentar reformular a teoria educacional no sentido de permitir a manutenção da norma em sala de aula, ou seja, um lugar em que professores e alunos se (des)encontram na satisfação narcísica com o seu ser sujeito. 0 fato é que a opção por esse caminho pedagógico opera como um mecanismo de defesa para não entrarmos em contato com o desespero em não saber as verdades sobre o ser, o que, nesse caso específico, representará o impossível abandono das certezas que determinam o método para constituir o sujeito educável.

No campo educativo, estamos mergulhados em nossas neuroses de querer educar o outro em nossa imagem e semelhança, pois em última instância, possuímos um amor por um sujeito que de certa forma acreditamos ser. Dessa forma, no outro, no sujeito a ser educado, projetamos a idéia de que este deve ser o que somos de melhor no campo do imaginário e, no caso da Educação, ele deve apreender o saber que nos circunscrevem e que nos faz sujeitos passíveis de sermos educados/adestrados. Portanto, o campo educacional encontrase centrado no fundamento da educação de que educar é algo que está diretamente relaci-

1. Utilizamos este termo, ilusão pedagógica, a partir da idéia desenvolvida por Lajonquière (1999) no seu livro intitulado: Infância e ilusão (psico) pedagógicas. 
onado com a modificação do comportamento do outro - a compulsão em educar ${ }^{2}$.

\section{Do fundamento da educação para a educação sem fundamento: o desencontro dos sujeitos na prática educativa}

Não podemos deixar de reafirmar que todos aqueles que praticam a atividade educativa percebem que, em sala de aula, a relação entre sujeitos falha e constitui-se no desencontro de sujeitos, mais propriamente, numa educação sem fundamento. Assim, apontamos para a ruptura com a tese pedagógica de que, na relação educativa, encontramos o outro, ou seja, nada sabemos a respeito do ser sujeito que se constitui no vínculo das relações que estabelecemos com os outros. Quando muito, temos uma precária idéia do que somos e fomos com o outro. Vivemos completamente alheios aos nossos acontecimentos e, a cada momento, vamos definindo regras que são apenas conforto para os nossos anseios em não saber ser sujeito. Nesse caso, não se pode negar que no campo educacional vive-se certo contra-senso, ou seja, quanto mais se teoriza nas formulações de teorias metodológicas de aprendizagem, menos se proporcionam as condições efetivas e, até mesmo, afetivas para o encontro com o outro. Nesse caso, de certo modo, as metodologias de ensino dificultam o acesso ao outro. Entretanto, o senso comum pedagógico insiste em estabelecer orientações e as condições para caminharmos numa efetiva relação educativa. Isso é um modo de caminharmos em direção à ilusão do possível encontro com o outro.

Paradoxalmente, o reconhecimento da situação de desencontro entre sujeitos que seria um contra-senso é que poderia criar as condições de efetivar conexões entre os sujeitos e destituir a ilusão de que sabemos educar. Os educadores em sala de aula podem analisar que o outro não corresponde ao pressuposto do seu saber pedagógico. As táticas educativas em sala de aula se passam como situações das quais muitas vezes se desconhecem os seus verdadeiros caminhos. Entretanto, como uma fuga do desespero em não saber educar e em oposição a essa situação, os debates educativos realizamse geralmente em torno de detalhes de metodologias de ensino e aprendizagem. No entanto, não podemos deixar de considerar que esses detalhes metodológicos educativos estão tornando o sujeito uma coisa, ou seja, o primordial da prática educativa está sendo desconsiderado, pois nessas situações de encontro, deveríamos buscar "estabelecer imediatamente laços íntimos de genuíno diálogo do que em transmitir uma doutrina" (Zuben, 2004, p. 47).

0 encontro com o outro como algo fenomênico e a relação é algo que sempre escapa. Radicalizando sobre essa relação entre sujeitos, questionamos se a existência do sujeito não seria uma ilusão moderna. Partindo da psicanálise, podemos posicionar o sujeito como a manifestação das formações do inconsciente - o sintomático retorno do recalcado - e, portanto, um ser em atuação que nada sabe sobre o ser sujeito. Estabelecemos algumas verdades provisórias do sujeito para que possamos acreditar no que somos, e minimamente estabelecermos regras do nosso funcionamento, principalmente, educativos. Nesse aspecto, nas relações entre o sujeito e a verdade, poderíamos

[...] dizer que somos obrigados pelo poder a produzir a verdade, somos obrigados ou condenados a confessar a verdade ou a encontrá-la. 0 poder não pára de nos interrogar, de indagar, registrar e institucionalizar a busca da verdade, profissionalizaa e a recompensa. [...] Afinal, somos julgados, condenados, classificados, obrigados a desempenhar tarefas e destinados a um certo modo de viver ou morrer em função dos discursos verdadeiros que trazem consigo efeitos específicos de poder. (Foucault, 1990, p. 180)

2. A compulsão em educar seria a realização de uma prática educativa que desconsidera o outro, ou seja, pautado nos fundamentos da educação, o educador de modo obsessivo coloca em ação sua prática educativa como a realização de atos mecânicos. 
A partir da epígrafe no início do texto, podemos dizer que a formação educativa no interior da família aponta o motivo para compreendermos o que impede o sujeito de realizar o encontro com o outro. Nesse caso, concluiríamos que o sujeito é o resultado de experiências subjetivas que adquirem no transcorrer de sua vida. Entretanto, como este se educa, pois nada sabemos em ser sujeito? Sobre qual tipo de encontro desejamos efetivar a prática educativa? Seria possível uma prática educativa no desencontro de sujeitos? Quando falamos de desencontro, estamos nos referindo a uma efetiva relação entre eu e tu e não algo que gire em torno do eu e isso. Sobre a relação entre eu e tu, podemos dizer:

A relação com o Tu é imediata. Entre o Eu e o Tu não se interpõe nenhum jogo de conceitos, nenhum esquema, nenhuma fantasia; e a própria memória se transforma no momento em que passa dos detalhes à totalidade. Entre Eu e Tu não há fim algum, nenhuma avidez ou antecipação; e a própria aspiração se transforma no momento em que passa do sonho à realidade. Todo meio é obstáculo. Somente na medida em que todos os meios são abolidos, acontece o encontro. (Buber, 2004, p. 59)

Entretanto, a nosso modo de relacionar pouco se mantém na estrutura entre eu e tu, ou seja, fazemos das relações jogos de conceitos; esquemas; fantasia; detalhes. Enfim, coisificamos o outro única e exclusivamente para que possa atender às nossas necessidades.

[...] a grande melancolia de nosso destino é que cada Tu em nosso mundo deve tornar-se irremediavelmente um lsso. Por mais exclusiva que tenha sido a sua presença na relação imediata, tão logo esta tenha deixado de atuar ou tenha sido impregnada por meios, o $\mathrm{Tu}$ se torna um objeto entre objetos, talvez o mais nobre, mas ainda um deles, submisso à medida e à limitação. (Buber, 2004, p. 63)
0 hegemônico em Educação é uma relação estabelecida a partir da fixação de um discurso de verdade sobre o sujeito (coisa), no qual este acaba por definir o encontro com o outro (coisa). Nesse caso, a prática educativa é vivida, predominantemente, na relação entre o eu e isso. Essa relação prevalece e, principalmente, funciona pelos motivos pelos quais somos educados e tratados exclusivamente como coisa para sermos mais operacionais e eficientes, contudo, menos vinculados e afetivos em relação ao outro. Podemos educar para a verdade em ser sujeito a ponto de responder prontamente a diversas situações de modo efetivo e produtivo. 0 que podemos fazer em termos de educação sem cairmos na ilusão da existência de uma verdade que nos lança para a crença no encontro entre sujeitos?

Como já nos referimos anteriormente, partimos da idéia de que nos lançamos para a vida a partir das nossas experiências subjetivas acumuladas, e são os pais e educadores que proporcionaram a nossa primeira experiência de envolvimento com o outro. Partimos da premissa de que de certo modo somos e vivemos provisoriamente a experiência de encontrar o outro. lsso de certo modo serve de fundamento e com certa importância para que tenhamos um pequeno ponto de sustentação para compartilhar a nossa crença em ser sujeito. Portanto, o paradoxo da nossa existência em ser sujeito é que essa crença de certa forma tem nos proporcionado as condições de vivermos algo em nossas vidas. Isso serve de base para que se estruture o nosso modo de ser e o tipo de relação com o outro. Entretanto, quem seria esse outro do nosso encontro, mais propriamente, do nosso desencontro?

Podemos pensar que o outro primordial do nosso desencontro é o voltar-se para si que nos deixa perdidos no labirinto do eu. Nesse caso, para que possamos encontrar o outro, não seria oportuno realizar primeiramente certo retorno de si a ponto de compreender-se a si mesmo? Portanto, o primeiro sujeito a encontrar é o nosso eu, pois como encontrar o 
outro se estamos perdidos de nós mesmos? Podemos nos conformar pensando que somente nos encontraremos pelo fato de estarmos perdidos de nós mesmos, contudo,

[...] como poderíamos encontrar-nos? Como o homem pode conhecer-se? É uma coisa obscura e velada, e se a lebre tem sete peles, o homem pode tirar sete vezes setenta destas e mesmo assim não poderá dizer: 'este sou o eu real e não uma aparência'. Além disso, mergulhar no poço da própria existência é um começo arriscado. Facilmente produziremos feridas que nenhum médico pode curar. E depois, para que isto seria necessário, quando tudo é testemunha do nosso ser? As nossas amizades e inimizades, nosso olhar, nosso aperto de mão, nossas lembranças, nossos esquecimentos, nossos livros e os traços de nossa caneta. Mas eis o meio para realizar o interrogatório mais importante. Olhe a jovem alma atrás da própria vida e pergunte-se: o que realmente amou até hoje? 0 que atraiu sua alma, o que dominou e ao mesmo tempo tornou-a feliz? Coloque à sua frente estes venerados objetos e eles, talvez, com seu ser e sua sucessão lhe darão uma lei, a lei fundamental de si mesmo. Compare estes objetos e observe como um completa o outro, o amplia, o supera e o transforma, até formar uma escada sobre a qual até agora você subiu a procura de si mesmo; a sua verdadeira existência, de fato, não está escondida dentro de você, mas muito acima de você ou daquilo que você considera o seu eu. Os verdadeiros educadores e mestres revelam o sentido originário e a matéria fundamental do ser, aquilo que não se pode absolutamente educar nem formar, é de difícil acesso por estar amarrado, paralisado: os seus educadores não podem ser nada mais que seus libertadores. E este é o segredo de toda formação: esta não dá membros artificiais, nariz de cera, olhos postiços - dons que somente a falsa imagem da educação pode dar. Esta é a verdadeira liberação, remoção de todas as ervas daninhas, lixos e parasitas que ameaçam as delicadas sementes das plantas, é transmissão de luz e calor, doce cair de chuva noturna, é imitação e veneração da natureza, quando esta se mostra materna e misericordiosa, e é aperfeiçoamento, quando prevê os terriveis ataques levando-os ao bem, quando estende um véu sobre as manifestações da sua alma madrasta e da sua triste loucura. (Nietzsche, 1999, p. 3)

A busca de si mesmo é desesperador e os pedagogos, de certo modo, em suas práticas, não reconhecem essa dificuldade e, como formação reativa, fazem da vida dos escolares a exigência insuportável de terem que lidar com um encontro não desejado em sala de aula e, principalmente, em nossas vidas ${ }^{3}$. 0 outro sinaliza um problema para ser vivido em termos de experiência humana, na qual, como muita dificuldade, tentamos estabelecer algumas trocas que não são muito bem sucedidas - para não dizer que são verdadeiros desastres. Essas situações podem ser observadas, principalmente, naquilo que orbita no campo do uso da palavra, pois falamos o que não pensamos e escutamos o que não foi dito. Vivemos em nossas relações o embate que denominamos de mal-entendido - para não dizermos mal-estar (Freud, 1990a).

As metodologias de práticas educativas constituem como uma negação do mal-entendido na tentativa de driblarmos a nossa impotência de termos que lidar com o não-saber o que fazer com o outro, que se encontra na espera de algo que o eduque. Portanto, as certezas educativas não passam de uma fuga de nós mesmos e um modo de não reconhecer a falta na experiência do encontro entre os sujeitos. Esses sintomas de negação da falta podem ser ampliados em nossos núcleos familiares e profissionais. Principalmente em lugares de baixa circulação de afeto, essas neuroses correspondem

3. A exigência do encontro possui suas táticas de ação e, a cada início de aula, o professor faz a chamada para verificar a presença do aluno e este, quando escuta o seu nome ser chamado, responde, prontamente, presente. 
a sintomas de negação da castração que se instauram nas estruturas do poder e se traduzem em práticas autoritárias, que nas escolas e fábricas constituem a autoridade perversa do professor/chefe - um modo sublimado do exercício da crueldade ${ }^{4}$.

Nesses casos, apesar de os sujeitos viverem próximos um do outro, principalmente no ambiente escolar, não conseguem vivenciar experiências humanas. Apenas realizam as trocas simbólicas que permitem o pleno funcionamento da sociedade de mercado, mas não se reconhecem no âmbito das relações humanas. Portanto, o fato de estarem próximos fisicamente uns dos outros não constitui a condição necessária para se realizar o verdadeiro encontro. 0 que fazem no máximo é o esboço do paradigma das relações afetivas hegemônica da classe social à qual pertencem, ou seja, numa sociedade cuja organização está pautada no capital financeiro, as relações entre sujeitos são regidas pelo mercado das coisas e não pela ordem dos afetos humanos. Esses tipos de sujeitos coisificados estão completamente fechados para qualquer tipo de vínculo afetivo. Para dimensionarmos essa falta de possibilidade de encontro com o outro, podemos ter como paradigma a máquina de abraçar de Temple, que a ela recorria quando precisava ser acolhida. 0 seu

[...] mecanismo tinha dois lados de madeira pesados e inclinados, talvez com um metro e meio por um metro cada, prazerosamente estofados com um enchimento espesso e macio. Eram ligados por dobradiças a uma prancha de base longa e estreita, criando uma calha do tamanho de um corpo e em forma de V. [...] Sua máquina de espremer funcionou exatamente como esperava, produzindo aquela sensação de tranqüilidade e prazer com que sonhava desde a infância. (Sacks, 1995, p. 269-70)

Queremos pontuar que a recorrência à invenção de Temple de sua máquina de abraçar não a qualifique como um sujeito coisificado, mesmo porque esta não dispunha de qualquer tipo de vínculo afetivo com os outros sujeitos em virtude do seu estado sintomático como autismo. Entretanto, essa máquina aponta para o fato de que vivemos presos em nós mesmos e assim queremos ficar. 0 outro na relação é uma máquina de abraçar que, quando inoportuno, esperamos poder desligá-lo. Nesse caso, compreendemos essa máquina como um ícone da nossa impossibilidade de encontrar o outro. Entretanto, quais seriam os motivos dessa nossa ilusão em querer encontrar o outro? Em poucas palavras, não queremos ficar a sós com nós mesmos, pois não conseguimos suportar as nossas próprias neuroses - o desamparo da solidão. Vivemos numa relação de necessidade pelo outro para que este possibilite as condições de projetarmos parte de nosso amor e ódio pelo o ser/sujeito que acreditamos existir habitado em nosso eu.

Partimos da tese de que não sabemos sobre os motivos de nossos encontros e, principalmente, as causas que nos impedem de estabelecermos vínculos verdadeiros com o outro. Uma relação que seja entre sujeito e sujeito e não entre coisa e coisa. Entretanto, o paradoxo encontra-se justamente por não sabermos radicalmente ser sujeitos verdadeiros. 0 que sabemos fazer resulta na construção da nossa sociedade que estabelece um modo operante do encontro sem troca, compromisso ou qualquer tipo de responsabilidade pelo outro. Esse modo de vida mobiliza um grandioso mercado de consumo, no qual fenomenicamente os sujeitos saem para a realização do encontro com o outro e consomem tudo que lhe é permitido para a sua realização. Preparam-se para um encontro que a priori está fadado a sua não-realização, pois necessitam consumir a fim de produzir a própria satisfação narcísica e muito menos produzir o encontro com o outro.

4. Nesse caso, penso o Daniel Gottlieb Moritz Schreber como educador que "era médico ortopedista e pedagogo, autor de cerca de vinte livros sobre ginástica, higiene e educação das crianças. Pregava uma doutrina educacional rígida e implacavelmente moralista, que objetivava exercer um controle completo sobre todos os aspectos da vida, desde os hábitos de alimentação até a vida espiritual do futuro cidadão" (Carone, 1995, p. 10-11). 
0 consumo desenfreado é um modo de lidar com o desespero do vazio que fica quando não existe troca de relações humanas, ou seja, no encontro, em vez de se estabelecer troca de relações humanas, ocorre somente um desencontro e o que resta somente são as trocas de coisas muitas vezes pouco compreendidas, e esse é o motivo pelo qual no cotidiano as nossas trocas e, até mesmo, as relações humanas mais íntimas são regidas por formas contratuais ${ }^{5}$.

Portanto, no desencontro de sujeitos e no encontro de coisas, os sujeitos, narcisicamente, estão fechados em si mesmo e buscam somente a própria satisfação egóica. Numa aglomeração em que se misturam sujeitos e coisas, chega-se a ponto de os sujeitos também serem confundidos com as coisas. Nesse emaranhado de coisas, poucos estão realmente se encontrando e, principalmente, compartilhando muito pouco a experiência humana em torno do amoródio ${ }^{6}$.

Não posso deixar de relatar uma situação bem determinada da minha infância para pensar a questão do encontro de sujeitos, qual seja, a lembrança de que as casas na praia onde passava as minhas férias escolares não possuíam muros para separar um quintal do outro. 0 que se tinha era apenas uma pequena cerca de arbustos que permitia uma visibilidade entre os moradores das casas e uma adorável sombra. A cerca era apenas para demarcar o terreno e entre seus arbustos tínhamos diversas passagens para o quintal do vizinho. Vivíamos uma situação muito peculiar na qual era possível passarmos de uma casa para a outra como se todos os quintais fossem unificados e isso permitia um modo muito ampliado de convivência entre as diversas famílias que ali passavam os seus dias de descansos. Era muito comum o preparo de festas comunitárias que geralmente eram programadas para os finais de semana, pois era o momento em que todos estavam presentes. Com essas práticas de festas e tendo as cercas como um símbolo para a demarcação do território e não para separar e impedir o encontro, tinham-se as condições de um convívio muito rico em termos de relações hu- manas: amoródio. Entretanto, hoje nesse mesmo lugar, o que encontramos não são mais os arbustos que denominamos como cerca viva e sim altos muros de tijolos que impedem que um morador de uma casa possa ver ou encontrar o seu vizinho ao lado. Podemos pensar que, no campo da ambivalência das relações humanas, o ódio prevaleceu e, nesse caso, passamos de um modo de convivência da cerca viva trocada por um muro - cerca morta. Resta sabermos os motivos que proporcionaram essas alterações físicas no modo de separar os quintais.

\section{A educação do desencontro: não queremos encontrar o outro}

Partimos da hipótese que a emergência dos muros resulta de uma trama das relações subjetivas que instituem a separação entre os sujeitos. Nesse caso, o fenômeno dos muros é apenas um indicativo para definir qual o tipo de relações humanas que se pretende estabelecer e, até mesmo, não se estabelecer entre os sujeitos. No entanto, o que se alterou primeiro, ou seja, foram nossas relações sociais que proporcionaram o crescimento dos muros ou as construções dos muros que alteraram as nossas relações sociais?

Muros e relações sociais se alteraram numa trama sem uma regra lógica, mas podemos afirmar que um pólo alimentou o outro, proporcionando as condições necessárias para uma sociedade que tem como sintoma o pleno isolamento do sujeito. Portanto, não foram os muros que vieram e depois deixamos de nos encontrar, mas uma mistura em que um fortalece o outro. Nesse caso, podemos não saber como se dá a somatória dessas forças, mas sabemos o seu resultado que seria a total falta de afetividade em relação ao outro. Desse modo, os muros apontam para o que não queremos saber, ou seja, o impossível encontrar o

5. Não seria por acaso que os contratos de compra e venda, assim como os casamentos, são todos registrados em cartórios.

6. Para a psicanálise, as pulsão de vida e pulsão de morte se direcionam unificadas em direção ao objeto. Portanto, torna-se possível o uso da palavra amoródio quando queremos expressar o trabalho da experiência humana. 
outro. Isso pode ser analisado na seguinte situação em que

[...] numa rua tranqüila de casas antigas e calçamento de pedras, foi abandonado um Honda Fit "com uma cabeça sobre o capô, e os corpos de dois jovens negros, retalhados a machadadas, no interior do veiculo'. As vítimas eram 'moradores da favela Camarista Meier e teriam sido executados pelo Comando Vermelho em razão de dívidas com o tráfico'. Até aqui o horror é ordinário: há sociopatas e malucos nas fileiras do crime. [...] A reação dos moradores foi tão chocante como as brutais mutilações. Vários moradores buscaram seus celulares para fotografar os corpos, e os mais jovens riram e fizeram troça dos corpos. (Calligaris, 2006, p. 10)

Nesse caso, a atuação do nosso ser desmascara que o outro não existe e se existe é somente como objeto de nossa satisfação pulsional. Portanto, o outro é uma coisa que não nos afeta, pois estamos bem protegidos por trás dos nossos muros e das nossas cercas elétricas. A tal fenômeno bizarro da nossa sociedade contemporânea, denominamos psicose das relações humanas, ou seja, podemos ser sujeitos plenos em nossas neuroses, mas fechados em nós mesmos no que diz respeitos às relações que estabelecemos com o outro. Nesse caso, no encontro com o outro, fazemos somente a projeção do eu e, nesse processo, queremos encontrar a realização daquilo que nos permita obter a plena satisfação. Quando por algum motivo estamos impedidos de projetar o eu em direção ao outro (as vítimas da favela), este não existe e não é passível da nossa compaixão.

0 que se pode compreender do resultado da psicose das relações humanas é que deixamos de encontrar o outro e nos perdemos no labirinto narcísico do encontro de si mesmo (Comte-Sponville, 1997). Em algum momento de nossas vidas, perdemos as condições psíquicas de estabelecermos algum tipo de experiência subjetiva que seja a compreensão do nos- so desencontro e, portanto, lançamos o ódio para qualquer tipo de situação que nos retrate essa situação de não-saber. Para não vivermos essa condição de não-saber, optamos em morar seguros e protegidos em nossas verdades e podemos dizer:

0 homem está muito bem defendido de si mesmo, da espionagem e do assédio que faz a si mesmo, e geralmente não enxerga mais que seu antemuro. A fortaleza mesma The é inacessivel e até invisível, a não ser que amigos e inimigos façam de traidores e o conduzam para dentro por uma via secreta. (Nietzsche, 2000, p. 266-267)

Qual seria essa via secreta que pode encaminhar o sujeito para o desencontro e, mais precisamente, quais seriam os lugares em que permaneceu possível a existência desse tipo de experiência humana sem despertar o ódio de não sabermos ser sujeito?

Constatamos que em nossa modernidade o encontro virtual tem se difundido como uma modalidade de comunicação e, até mesmo, de educação dos sujeitos. Podemos pensar na hipótese de que o virtual surge como uma modalidade de encontro de sujeitos surgida com o fortalecimento dos muros. Pensamos estar bem defendidos por trás de nossas fortalezas, para não dizer dos teclados. Nesse caso, não seria por acaso que assistimos a um aumento do oferecimento de cursos de ensino a distância que, na perspectiva do nosso entendimento, é um modo racionalizado em não reconhecer a falência do ensino presencial, pois a tese pedagógica da prática educativa no encontro de sujeitos não mais se coaduna com as exigências para a plena escolarização. Vivemos na educação a dificuldade de construir uma via para a crise do sujeito e, mais propriamente, o reconhecimento consciente da falência da nossa possibilidade de encontro. Entretanto, o que seria exatamente o fortalecimento dos muros e teclados como um sintoma social da nossa contemporaneidade? 
No âmbito da teoria freudiana, muros e teclados constituem uma tentativa de manter a verdade do sujeito, um modo de manter fixo em nosso saber educar - a nossa intolerância narcisista da pequena diferença perante o outro que não aprende (Freud, 1990a). 0 fato de muro/teclado impedir o olhar do outro, não pode deixar de sinalizar que este também impede o olhar daquele que é olhado. Assim, o muro/teclado mantém a ordem e a disciplina escolar, trancafiando e impedindo o olhar e a circulação física do eu e do outro.

A partir dessa situação da hegemonia dos muros/teclados, indico um sintoma da nossa modernidade, qual seja, empobrecemos as nossas relações humanas. Isso acaba por atuações que impedem de fazermos vínculos com o outro, pois demanda responsabilidade, compartilhamento de afetos. Enfim, encontrar o outro exige a troca de experiência humana - o trabalho para que se amenize o conflito entre o eu e o outro.

0 outro pode ser o inferno da relação e, portanto, para evitar o conflito, a saída seria a recusa da existência do outro. Para Freud (1990a), a relação com o outro se constitui na incerteza da realização da nossa felicidade.

Nossa possibilidades de felicidade sempre são restringidas por nossa própria constituição. Já a infelicidade é muito menos difícil de experimentar. 0 sofrimento nos ameaça a partir de três direções: de nosso próprio corpo, condenado à decadência e à dissolução, e que nem mesmo pode dispensar o sofrimento e a ansiedade como sinais de advertência; do mundo externo, que pode voltar-se contra nós com forças de destruição esmagadoras e impiedosas; e, finalmente, de nossos relacionamentos com os outros homens. (p. 84-85)

Nesse caso, queremos evitar qualquer tipo de contato que possa favorecer qualquer tipo de vínculo afetivo mais profundo e, no caso da Educação, o vinculo entre o aluno e o professor.
Passamos a viver numa sociedade em que se permite apenas vínculos e contatos parciais, pois temos o medo do contato (Canetti, 1995). Para este, esse medo é decorrente do fato de que

\section{[...] não há nada que o homem mais tema} do que o contato com o desconhecido. Ele quer ver aquilo que o está tocando; quer ser capaz de conhecê-lo ou, ao menos, de classificá-lo. Por toda parte, o homem evita o contato com o que lhe é estranho. (p. 13)

Para se evitar o contato, erguemos muros e estes podem ser divididos, basicamente, em dois tipos: os muros físicos e os muros morais. Eles se apresentam na relação inversa, ou seja, quando um cresce, o outro diminui. Assim, observamos sociedades com poucos muros físicos, mas que estabelecem muros morais e outras sociedades nas quais existe grande quantidade de muros físicos e têm-se poucos muros morais. Assim, os muros físicos e morais são uma barreira para tentar evitar o outro, pois

\section{[...] tal aversão ao contato não nos deixa nem quando caminhamos em meio a outras pessoas. A maneira como nos movemos na rua, em meio aos muitos transeuntes, ou em restaurantes, trens e ônibus, é ditada por esse medo. Mesmo quando nos encon- tramos bastante próximo das pessoas; mes- mo quando podemos observá-las bem e inspecioná-las, ainda assim evitamos, tanto quanto possivel, qualquer contato com elas. (Canetti, 1995, p. 13)}

Em nossa sociedade, o que prevalece nas relações humanas modernas é a tolerância zero para com o outro. lsso seria uma relação de sujeitos sem nenhum tipo de aprofundamento de vínculo de amoródio, ou seja, não existe aparentemente passado ou futuro, o que se tem é somente o presente, e este é regido pelo princípio de prazer. Entretanto, o desencontro está totalmente regido por um passado e um futuro e a plena negação do presente. Nesse 
caso, no desencontro, nega-se o presente, pois o outro da relação existe somente para satisfazer uma ilusão de encontro entre sujeitos. Situamos o sujeito preso ao passado e fixado no presente, pois repete seu sintoma - o retorno do recalcado. 0 futuro é uma projeção que está circunscrita em sua pequena tolerância narcisista da sua verdade sobre o ser sujeito, pois não consegue libertar-se do gozo proporcionado pelo próximo encontro com o sujeito (coisa).

Seria o surgimento dos muros/teclados uma barreira física de tentar impedir as relações humanas? Diríamos que é um modo operante de nos mantermos afastados uns dos outros, mas na tentativa de impedir o desagradável reconhecimento de que se vive uma situação de desencontro, formulamos sintomaticamente a ilusória superficialidade com que os sujeitos vivem os encontros e com o qual fazemos nossos vínculos com o outro. Como num castelo, podemos convidar ou não o outro para que entre em contato com a nossa privacidade. Contudo, vivemos numa sociedade em que existe um apelo para que a privacidade seja invadida e que isso seja um direito de todos. Nesse caso, não podemos esquecer que programas televisivos como Big Brother Brasil (BBB) estabelece elevados indices de audiência. Vivemos uma sociedade que possui uma vontade de saber o que outro faz por de trás de seus muros e, no caso do BBB, mais propriamente das paredes dos quartos e banheiros. Diriamos um direito de quase todos, pois a exclusividade de acompanhar por 24 horas as imagens das inúmeras câmeras de vídeos espalhadas por todos os cômodos da casa do BBB, principalmente quartos e banheiros, são para aqueles que pagam pelo direito a transmissão pela televisão por assinatura. Temos assim em nossa modernidade o voyeurismo institucionalizado como base de um lucrativo negócio televisivo.

Pautado na teoria freudiana, podemos analisar que esse desejo de ver e escutar o que acontece por de trás das paredes estaria circunscrito na fantasia sexual da criança em relação à vida amorosa de seus pais, ou seja, a questão para ela é: o que eles fazem trancados no quarto e por quais motivos eu não posso entrar? Assim, as paredes educam as crianças para que percebam que o outro nem sempre pode ser encontrado, pois é preciso esperar o seu momento para o desencontro. Um núcleo familiar que circula afeto permite à criança esse tempo da espera. No caso da família estruturada na psicose das relações humanas, esta não permite à criança sustentar esse tempo de espera e isso proporciona uma ansiedade pela permanência do seu isolamento. Ela passa a ser educada a conviver com o isolamento e será essa modalidade de atuação que repetirá em suas futuras relações afetivas em seus desencontros e fará de tudo para que possa encontrar o outro, mesmo que para tanto precise anular a própria existência. Nesse caso, podemos compreender os fortalecimentos e crescimentos dos muros/teclados como a ampliação desse sintoma, qual seja, a banalização do encontro ou o fortalecimento da psicose das relações humanas.

Temos como hipótese de trabalho que perdemos a possibilidade do tempo da espera para o desencontro com o outro. 0 encontro aparece como um modo de fuga do desespero em constatar que não há nada a encontrar no outro que venha garantir a verdade em ser sujeito. Para não nos defrontarmos com essa situação, temos como modo de conduta social sã, basicamente, duas possibilidades: a invasão ou o impedimento.

Tendo essas duas possibilidades de conduta social para pensarmos a questão do desencontro de sujeitos, seria oportuno analisar até que ponto o paradigma do muro/teclado serve de referência para fundamentar essa temática e, até que ponto, este serve de modelo para estabelecer o eixo educativo, ou seja, estaríamos sendo educados para evitarmos ou invadirmos uns aos outros?

\section{O desencontro entre os sujeitos e a questão do fracasso escolar}

No âmbito da Educação, não podemos deixar de citar a escola para analisar essa ques- 
tão, qual seja, a educação tem como base a questão do encontro entre sujeitos, entretanto, a sua prática realiza-se no paradoxo do desencontro entre os sujeitos. Seria esse o fato de que por vários aspectos em que muros/teclados são tão exaltados em seu funcionamento?

Consideramos que os problemas que mais se destacam na escola entre todos são: a falta de aprendizagem e a perda da disciplina no ambiente escolar. Esses dois aspectos destacam-se pela identificação imediata daquilo que se denomina como fracasso escolar. Entretanto, o que seria o fracasso escolar? Atualmente o senso comum identifica o problema do fracasso escolar com os problemas de aprendizagem e a reprovação do aluno na série escolar em que se encontra matriculado. As políticas públicas na área da Educação têm enfrentado esses problemas modificando - mais propriamente, alterando - o processo de avaliação do aluno, ou seja, temos incorporado no sistema de ensino mecanismos que buscam avaliar o aluno na totalidade e isso tem sido o argumento facilitador para que os alunos deixem de ser reprovados. Na prática, isso tem destituído a reprovação de alunos que não dominam o saber específico das disciplinas do componente curricular.

Sobre a questão da avaliação escolar em meus anos de trabalho em escola pública, presenciei o absurdo de um professor de uma matéria especifica dizer que aluno não tem condições em passar em sua disciplina e os outros professores presentes votarem pela aprovação do aluno. Toda essa manobra pedagógica tem como finalidade diminuir os índices de reprovação. Portanto, nas escolas, eliminaram os problemas de aprendizagem tirando a própria aprendizagem como um elemento primordial da prática educativa, ou seja, o aluno não precisa mais dar prova pública que sabe para obter a sua avaliação escolar. 0 saber passou a ser considerado como um muro impeditivo que o aluno tinha que trabalhar para escalar penosamente no sentido obter o mérito de passar de ano. 0 problema escolar é resolvido eliminando-se o próprio problema. Sem esses muros, as estatísticas agora indicam que não temos mais o fracasso escolar. Entretanto, a resultante do paradigma do muro/teclado versus o fracasso escolar vai se apresentar em níveis superiores, no momento em que aluno ingressa no Ensino Médio e não sabe escrever ou fazer contas de dividir e de multiplicar. Temos assim consolidado um sistema educacional em que as crianças e os adolescentes não aprendem. Já é o momento de que as práticas educativas tenham como base em seus formuladores teóricos a postura crítica pela qual se pode identificar uma crise na idéia moderna de sujeito, ou seja, que toda formulação teórica no campo pedagógico possa se estruturar no impossível educar no desencontro entre sujeitos ${ }^{7}$.

Os especialistas em Educação procuram a causa desse problema pedagógico como aquele que busca a cura para uma doença, qual seja, o procedimento terapêutico/pedagógico é pautado no diagnóstico e, em seguida, aplica-se o remédio. Para os diagnósticos, são aplicados questionários, entrevistas, visitas, comparações com o objetivo de identificar os motivos por que os alunos não aprendem. Em seguida, é afirmado o melhor caminho para a cura, ou seja, os cursos de capacitação para os professores que, de certo modo, nas palavras dos especialistas, são peças centrais que garantem uma alteração no procedimento didático e, por conseqüência, uma melhora no desempenho do aluno. Para confirmar o tamanho desse êxito, são aplicadas formas de controle por meio de uma ostensiva avaliação. Esses mecanismos confirmam que a escola destravou e derrubou os muros/teclados que impedem a passagem do aluno e esta passou a funcionar em pleno fluxo para sua passagem na escola. Entretanto, como um campo de batalha, os alunos passam a exercer outras táticas de resistência aos novos ensinamentos praticados na escola, pois sempre se erguerão novos muros/teclados que devem ser derrubados. 0 que os alunos indicam no problema escolar é que os pedagogos não querem entrar em contato e que, há muito tempo, o sujeito

7. Não podemos deixar de lembrar que, para Freud (1990b), existem "três profissões impossíveis - educar, curar e governar" (p. 341). 
que eles acreditam existir nas relações educativas não existe mais e, mais propriamente, o reconhecimento do não saber como educar.

Analisamos que o reconhecimento do desencontro dos sujeitos nas relações educativas seria um passo no sentido de se constituir numa prática não cega de si mesma, mas mais propriamente em algo condizente com a vida do que ficarmos nos fixando em nossas manias pedagógicas do que é ser sujeito. Entretanto, os pedagogos estão muito bem protegidos e não tocam em um só tijolo de seus muros e não abandonam os teclados das altas tecnologias de ensino, pelo contrário, buscam cada vez mais se fortalecer em suas muralhas/eletrônicas do seu saber educar.

Os alunos procuram encontrar nas escolas espaços não ocupados e demarcam os seus territórios em oposição ao avanço inimigo. Temos assim no campo da educação escolar uma batalha política sobre a questão do sujeito. Nossa hipótese central de trabalho, para se pensar a prática educativa como um desencontro de sujeito - o denominado problema pedagógico -, é um modo de a escola reproduzir em seu interior o que ocorre na sociedade: a anulação da diferença pelo nãoreconhecimento da própria alteridade.

Neuroticamente os educadores de plantão não aceitam essa situação de que não há sujeito idealizado presente na relação educativa, pois de certo modo isso seria destituir-se também o ser ideal e, principalmente, o seu saber ser sujeito. Portanto, concluímos que toda relação educativa inexiste e, paradoxalmente, existe, pois de certo modo podemos ser plenamente educados.

Uma relação crítica no campo educacional estaria na estrutura de pensamento de que teoria/prática educativa não pode se sustentar nos a priori pedagógicos. Todos os problemas disciplinares dos alunos podem ser dimensionados como uma tentativa de sinalizar sua não-existência no interior das relações educativas, ou seja, fazem de tudo para indicar a sua tênue presença perante o outro e sua fragilidade em ser sujeito.

A não-compreensão teórica desse fato no interior das escolas tem como conseqüência a perda do significado do trabalho educativo e, mais propriamente, as aulas acabaram por se tornar um lugar em que não acontecem as conexões com a cultura escolar - trocas simbólicas. Entretanto, não se pode deixar de considerar que outros tipos de conexões, mais propriamente fluxos, desenrolam-se na escola e esta passa a ser um território para outros tipos de ensinamentos que denominamos contracultura.

Pelo fato de tanto o aluno como o professor perderem o sentido de realizar o trabatho escolar, o ambiente escolar deixou de proporcionar as condições necessárias para que se ocorra a prática educativa? Algo ocorre nesse campo de batalha pela existência do sujeito educável e, nesse aspecto, estamos nos referindo diretamente ao campo político, pois se permite como resultado dessa luta apenas a existência de um tipo de sujeito e que este seja primordialmente produtivo e permita a reprodução da ordem social vigente. Nesse aspecto, na radicalidade, a prática educativa, como um desencontro de sujeito, somente proporciona a produção e reprodução das relações hegemônicas da sociedade da psicose das relações humanas. Entretanto, há algo de bizarro no encontro/ desencontro de sujeitos, ou seja, não se entende o resultado do trabalho educativo. São esses desencontros que de certo modo abrem as fendas no saber pedagógico e evidenciam a fragilidade desses saberes educativos. A negação do não saber educar transparece na parte que tange aos pedagogos, pois tudo aquilo que não está em seu alcance teórico são denominados como problemas educativos e devem ser eliminados nada se quer saber sobre o não saber das relações entre os sujeitos no desencontro. Contudo, por mais que se faça controle da Educação não se sabe como esta funciona, portanto, uma má notícia para os pedagogos - não se pode esconder que entre os sujeitos da prática educativa, estando presentes ou a distância, tem-se o desencontro e, sobre isso, por mais que se controle e se vigie, nada sabemos sobre os resultados das relações humanas - o desamparo de não sabermos educar. 


\section{Referências bibliográficas}

BETTELHEIM, B. 0 coração informado: autonomia na era da massificação. Tradução de Celina Cardim Cavalcanti. Rio de Janeiro: Paz e Terra, 1985

BUBER, M. Eu e Tu. Tradução de Newton Aquiles Von Zuben. São Paulo: Centauro, 2004.

CALLIGARIS, C. Apocalipse agora. Folha de S. Paulo, llustrada, 02.03.2006. p. 10.

CANETTI, E. Massa e poder. Tradução de Sérgio Tellaroli. São Paulo: Companhia das Letras, 1995.

CARONE, M. Da loucura de prestígio ao prestígio da loucura. In: SCHREBER, D. P. Memórias de um doente dos nervos. Tradução de Marilene Carone. Rio de Janeiro: Paz e Terra, 1995.

COMTE-SPONVILLE, A. Tratado do desespero e da beatitude. Tradução de Eduardo Brandão. São Paulo: Martins Fontes, 1997.

FOUCAULT, M. Microfísica do poder. Tradução de Roberto Machado. Rio de Janeiro: Grall, 1990.

FREUD, S. 0 mal-estar na civilização (1930 [1929]). In: Obras Completas. v. XXI. Tradução de Jayme Salomão. Rio de Janeiro: Imago, 1990a.

Prefácio a Juventude Desorientada de Aichhorn (1925). In: Obras Completas. v. XIX. Tradução de Jayme Salomão. Rio de Janeiro: Imago, 1990b.

LAJONQUIÈRE, L. de. Infância e ilusão (psico)pedagógicas: escritos de psicanálise e educação. Petrópolis: Vozes, 1999.

NIETZSCHE, F. W. Humano, demasiado humano: um livro para espíritos livres. Tradução de Paulo César de Souza. São Paulo: Companhia das Letras, 2000.

Schopenhauer como educador. Tradução de Adriana Maria Saura Vaz. Campinas: FE/Unicamp (mimeo), 1999.

SACKS, 0. Um antropólogo em marte: sete histórias paradoxais. Tradução de Bernardo Carvalho. São Paulo: Companhia das Letras, 1995.

ZUBEN, N. A. von. Introdução. In: BUBER, M. Eu e Tu. Tradução de Newton Aquiles von Zuben. São Paulo: Centauro, 2004.

Recebido em 23.10.06

Aprovado em 13.08.07

Rogério Rodrigues, graduado em Educação Física pela UNESP, mestre e doutor em Educação pela UNICAMP, é docente adjunto da Universidade Federal de Itajubá - UNIFEI - e desenvolve projeto aprovado pela FAPEMIG intitulado: Clínica da cultura: a educação e a crueldade. 